\title{
Effect of Organic Substrates on the Growth and on the First Yield of Local Bulgarian Red Wine Variety "Mavrud"
}

\author{
Ivan Tsvetkov*, Teodora Dzhambazova \\ AgroBioInstitute, 8, DraganTsankov Blvd., 1164 Sofia, Bulgaria \\ *Corresponding Author: ivantsvetkov@abi.bg
}

Copyright (C 2014 Horizon Research Publishing All rights reserved.

\begin{abstract}
The aim of this study is to determine the effects of some organic substrates on growth characteristics and yield of local Bulgarian grapevine variety "Mavrud". In parallel, organic and conventionally cultivated experimental plants were used. Concerning growth behavior indexes, in generous, the plants cultivated by conventional agriculture methods showed similar results to organic agriculture variants in all observed parameters compared with the nontreated controls. New organic substrate Kompovet B4 ${ }^{\circledR}$ appeared to be the most convenient, confirming the results from the first and from the second year of the experiments. That could be an encouragement for including this substrate in the further grapevine organic farming technologies. Regarding the excellent quality of planting material as well as the novel forced greenhouse plant production methodsthe first berry clusters were formed at the second year, instead of the third one (usually, the grapevines start harvesting on third year after cultivation). First obtained fruits in organic farming experimental field have a typical variety cluster form and raisin shape.
\end{abstract}

Keywords Grape, Organic Farming, Growth Characteristics, Sustainable Agriculture, Cv. Mavrud

\section{Introduction}

Grape is a perennial crop that, compared to other crops, has relatively low nutritional needs and adapts well to marginal soils (Pongracz, 1978 [1]). These features make organic grape production a technically feasible, economically attractive and sustainable activity. About $70 \%$ of the worldwide organic grape production area was located in the EU-27, where Italy, France and Spain were the main producers (Eurostat, 2008 [2]). Bulgaria is one of the European countries with fast development of organic viticulture with already certified 513 ha and 1404 ha organic vineyards under the process of certification (MAF, 2011 [3]).
Selection of quality grapevine varieties with high adaptation to the environmental conditions and tolerance to pests/diseases is very important both for organic and conventional viticulture (Tsvetkov et al., 2005 [4]). Organic vineyard requires specific fertilizers, training operations to facilitate pruning (a critical practice), spraying and harvesting (Guesmi et al., 2012 [5]). A significant part of organic livestock manure is directly applying in organic crops as fertilizer substrates that close the cycle of organic production (Sorensen \&Rubaek, 2012 [6]). Farming systems without manure showed the severest loss in soil organic matter over time. Manure amendment to soils, as an attribute of mixed farming systems, is proven again to exert positive effects (Fließbach et al., 2007 [7]). Usually the animal production is concentrated in identified regions, different that crop production ones which made not cost effective to transport manure for utilization in other areas. For this reason, alternative organic substrates are used which very often are obtained by composting of residues from crop production and/or its relevant industries (Tsvetkov et al., 2010 [8]). The aim of this work is to study the effects of manure as a basic organic substrate and new certified one "Kompovet B 4"on growth behavior and yield of local Bulgarian grapevine variety "Mavrud". In addition, conventional managed control is also included.

\section{Materials and Methods}

\subsection{Plant Material}

Mavrud is an local red wine variety, cultivated only in Bulgaria from old times. It is area specific variety spread originally in the region of Assenovgrad at the food of Rhodopimountain. The wines produced from this variety have a deep ruby colour, enough tannin and acids in reserve and a typical pleasant flavour in which one can detect the taste of tendrils and blackberry. The wines develop perfectly when they are in contact with oak wood and 
acquire a strong, complex flavour with a mild, dense and harmonious taste. In the present work we used Agrobioinstitute selected Mavrud candidate clone. In vitro originated scion buds were "omega" grafted on rootstock SO4 (Vitisberlandieri x Vitisriparia). Planting material were produced by forced greenhouse "cartonage" method (Babrikov et al., 1989 [9]). Grafted plants were planted 4,5 months after stratification (at the end of May) in organic and in conventional experimental fields. All grapevine plants were cut in February regarded to modify Mozer casting.

\subsection{Organic Substrates}

The solid cow manure and Kompovet $\mathrm{B} 4^{\circledR}$ organic substrate used in this study were composted, added as fertilizer (5 1 per plant) and mixed in the upper layer of soil by disking. Before sampling, both substrates had been stored for more than 5 months in an uncovered heap placed outdoors, and had been composting during the storage. The substrates were placed in closed containers 1 month before their applications.

\subsection{Biometric Analyses}

Effect of organic substrates on the growth behavior indexes and on the first yield were reported at 14 months and at 17 months after planting. We used 20 individual plants per each treatment i.e. totally 80 individual plants. Observed growing parameters were length of the shoots, base diameter, number of leaves, shoot thickness, total number of berry clusters, total yield, mean weight of 1 cluster and mean weight of 1 berry. Average data were used for each observed parameter.

\section{Results and Discussion}

\subsection{Effect of the Organic Substrates on the Growth}

Related to the growth dynamic, in generous, the plants cultivated by conventional agriculture methods showed similar results than organic agriculture variants in all observed growth parameters compared with wicked one in the non- treated control (Table 1).

Table 1. Effect of organic substrates on the growth parameters*

\begin{tabular}{|c|c|c|c|c|}
\hline Variant & $\begin{array}{c}\text { Length of } \\
\text { the shoots } \\
/ \mathrm{cm} /\end{array}$ & $\begin{array}{c}\text { Base } \\
\text { diameter } \\
/ \mathrm{mm} /\end{array}$ & $\begin{array}{c}\text { Number of } \\
\text { leaves }\end{array}$ & $\begin{array}{c}\text { Shoot } \\
\text { thickness } \\
/ \mathrm{mm} /\end{array}$ \\
\hline $\mathrm{V} 1$ & 210.1 & 29.4 & 72.7 & 19.7 \\
\hline $\mathrm{V} 2$ & 175.7 & 29.2 & 70.1 & 18.2 \\
\hline $\mathrm{Vk}$ & 167.4 & 28.8 & 68.3 & 18.0 \\
\hline $\mathrm{CAV}^{* *}$ & 234.3 & 32.2 & 78.1 & 20.8 \\
\hline
\end{tabular}

Legend:

V1- Kompovet B $4^{\mathbb{B}}$ bioorganic substrate from Biovet Pestera Ltd.

V2- nature fertilizer/manure/

Vk- non- treated control

* mean values

** CAV- plant controls cultivated by conventional agriculture methods
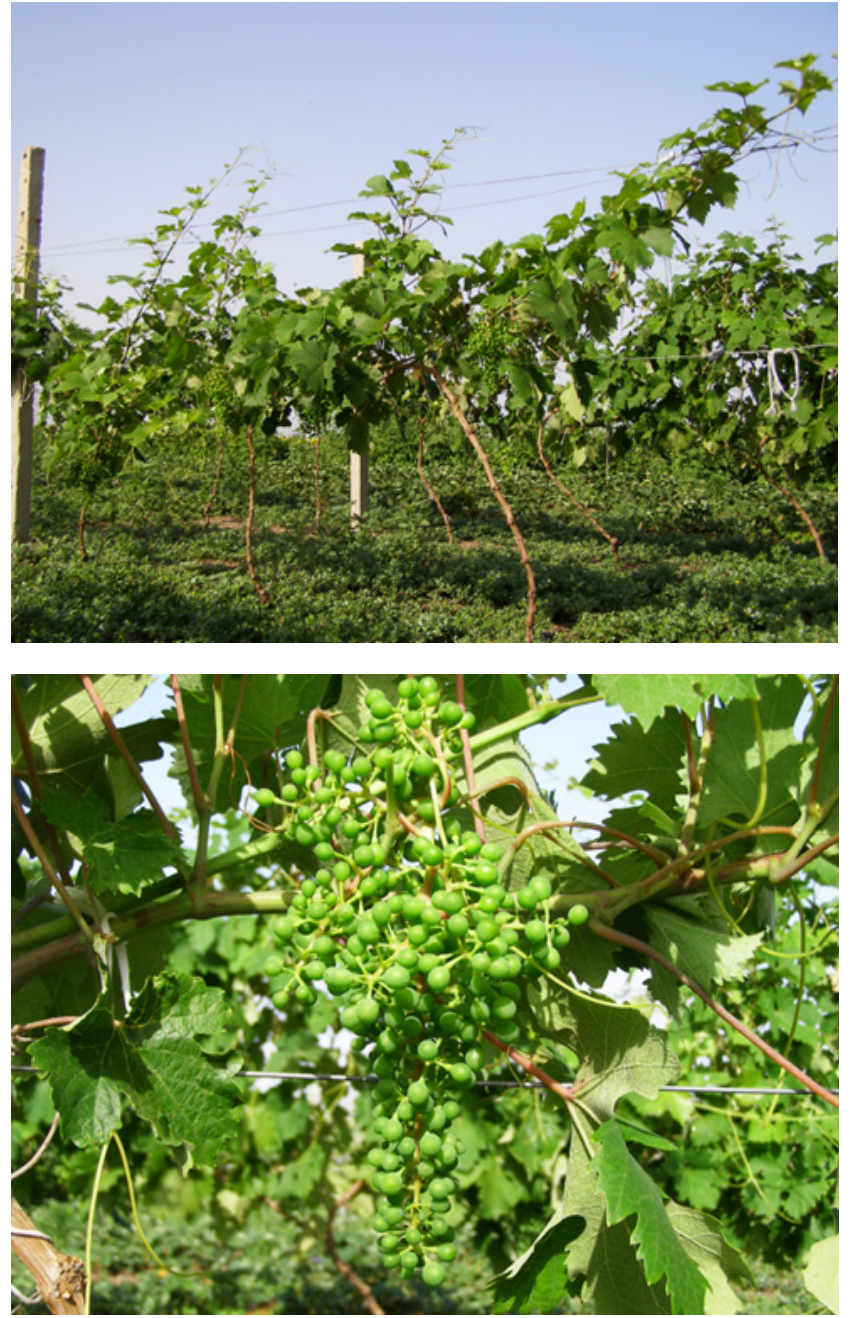

Figure 1. Formed first berry clusters of the organic experimental plants

That's could be encourage for the further enlarge grapevine organic farming areas in the region. Depending on the crop, soil, and weather conditions, organically managed crop yields on a per-ha basis can equal those from conventional agriculture, although it is likely that organic cash crops cannot be grown as frequently over time because of the dependence on cultural practices to supply nutrients and control pests (Pimentel et al., 2005 [10]).Organic substrates have been found similarly to improve vine balance and reduce disease and pest pressure in the vineyard, as well as suppress weed growth (Lanini et al., 2011) [11].Research has also linked increases in natural predation on pest populations. In our experiments, only standard dose sulfur and Nimazal ${ }^{\circledR}$ were used for plant protection again fungal and insect diseases. Until now, we have not observed any disease infection symptoms during the two vegetation cycles. Karkleliene et al. (2009)[12] reported similar successful applications of Nimazal ${ }^{\circledR}$ for effective pest biocontrol in organically grown carrot cultivars.

Use of organic waste substrates stimulated vine growth, shoot length, nutrient uptake, pruning weights yields and fruit quality (Pinamonti 1998 [13]; Coventry et al., 2005 
[14]; Guerra and Steenwerth, 2012 [15]). Our results showed statistically insignificant differences in growth parameters between organic substrates variants as well as between organic and conventional growing ones. However, a difference of $16,33 \%$ in length of the shoots were observed in favor of Kompovet B4 ${ }^{\circledR}$ organic substrate variant compared with the manure one. In this case, appeared to be convenient for organic viticulture application confirming its positive effect reported in our previous experiments (Tsvetkov et al., 2005, 2008, 2010 [16], [17], [18]).Especially for the region, added advantage is the proximity of the source for the Kompovet $\mathrm{B} 4^{\circledR}$ organic substrate that from another point of view is a waste product of an industrial production. The lack of sources of organic manure nearby, and additional ecological benefits for the environment make use of the Kompovet $\mathrm{B} 4^{\circledR}$ organic substrate very efficient from an economic and environmental perspective.

According to Villanueva- Rey et al., (2013) [19] many producers have initiated or have already accomplished the conversion towards field operations that improve the environmental profile of wine production having mind the reduction in wine sales due to the world economic crisis (OIV, 2012) [20]. Hence, both organic and conventional viticulture have begun to applied novel and attractive agricultural techniques. In this regard, proper selection of varieties and production methods of planting material is crucial to the quality and efficiency of the final productions. In our experiments, regarding to the excellent quality of planting material as well as the novel forced "cartonage" methods- the first berry clusters were formed 14 months after cultivation (Figure 1).

\subsection{Effect of the Organic substrates on the First Yield}

Mavrud is a late ripening variety - in the Plovdiv region the grapes ripening at the beginning of October (Figure 2). The first harvesting results are presented on Table 2.

Table 2. Effect of organic substrates on the first yield*

\begin{tabular}{|c|c|c|c|c|c|}
\hline Variant & $\begin{array}{c}\text { Total } \\
\text { number } \\
\text { of plants }\end{array}$ & $\begin{array}{c}\text { Total } \\
\text { number of } \\
\text { berry } \\
\text { clusters }\end{array}$ & $\begin{array}{c}\text { Total } \\
\text { yield } \\
/ \mathrm{kg} /\end{array}$ & $\begin{array}{c}\text { Mean } \\
\text { weight of } \\
1 \text { berry } \\
\text { clusters } \\
/ \mathrm{g} /\end{array}$ & $\begin{array}{c}\text { Mean } \\
\text { weight } \\
\text { of } \\
1 \text { berry } \\
/ \mathrm{g} /\end{array}$ \\
\hline $\mathrm{V} 1$ & 20 & 45 & 5.23 & 116.22 & 1.83 \\
\hline $\mathrm{V} 2$ & 20 & 36 & 4.15 & 115.26 & 1.78 \\
\hline $\mathrm{Vk}$ & 20 & 34 & 3.94 & 115.78 & 1.80 \\
\hline $\mathrm{CAV}^{* *}$ & 20 & 49 & 5.83 & 119.02 & 1.87 \\
\hline
\end{tabular}

Legend:

V1- Kompovet B $4{ }^{\circledR}$ bioorganic substrate from Biovet Pestera Ltd.

V2- nature fertilizer/manure/

Vk- non- treated control

* mean values

** CAV- plant controls cultivated by conventional agriculture methods in Experimental Station of Viticulture- Septemvry
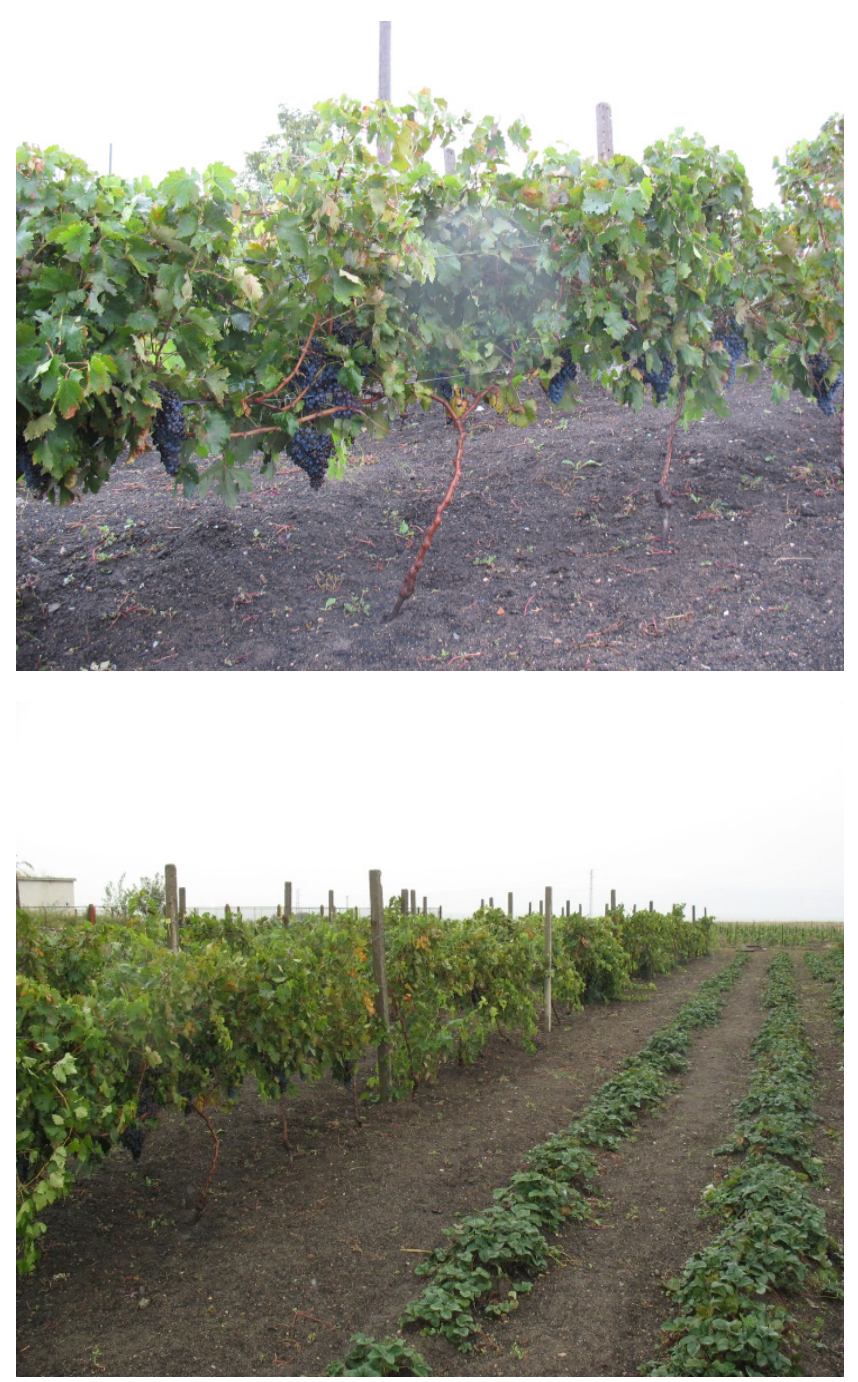

Figure 2. First harvesting of the local red wine variety Mavrud

Usually, the grapevines start harvesting on third year after cultivation. The berry clusters total yield until now do not give us the chance for more representative analyses. Nonetheless, the results confirmed again that organic variants shows the similar parameters as the plants cultivated by conventional agriculture methods. First obtained fruits in organic farming experimental field have a typical variety cluster form and raisin shape.

\section{Conclusions}

Bioactive organic substrate Kompovet $\mathrm{B} 4{ }^{\circledR}$ could be successfully applied in organic farming practices as a replacement or in addition to regular manure.

Experimental plants cultivated by conventional agriculture methods showed similar results than organic agriculture variants in all observed parameters. These features may make organic grape production in the Plovdiv region a technically feasible and economically attractive.

Traditional organic farming technologies could be promising adopted in conventional viticulture to make it 
more sustainable and ecological.

More studies have to be done to investigate single management effects and their combinations in order to evaluate the environmental role and value of different farming systems.

\section{REFERENCES}

[1] Pongracz, D., 1978. Practical Viticulture. David Philip (eds.), Cape Town, South Africa, pp. 11-29.

[2] Eurostat, 2008.Agriculture statistics. Main results 2006-2007. Available on line in http://epp.eurostat.ec.europa.eu (25 January 2009).

[3] Ministry of Agriculture and Food, 2011.Annual Report for State and Perspectives of Bulgarian Agriculture. (MAF eds.), pp. 54-59.

[4] Tsvetkov, I., Atanassov, A., Jankulova, M., Vulchev, V., Todorov, I., Pandeliev, S., Katerov, K., Atanassov, I., Hvarleva, T., Tsvetkov, Y., Genov, I., Dzambazova, T., Antonov, I., Marinov, L., Dimitrov, E., Panamska, M., Varadinova, G., Slavova, K., Atanassov, I., Shishmanov, G., N. Ivanova and M. Laginova, 2005.Grapevine Plant Genetic Resources- Improvement, Preservation and Biodiversity.Biotechnology \& Biotechnology Equipment, 19: 13- 21.

[5] Guesmi, B., Serra, T., Z. Kallas and J. Roig., 2012.The productive efficiency of organic farming: the case of grape sector in Catalonia. Spanish Journal of Agricultural Research 10(3): 552-566.

[6] Sorensen, P. and G. Rubaek, 2012.Leaching of nitrate and phosphorus after autumn and spring application of separated solid animal manures to winter wheat. Soil Use and Management, 28: 1-11.

[7] Fließbach, A., Oberholzer, H., Gunst, L. and P. Mader, 2007. Soil organic matter and biological soil quality indicators after 21 years of organic and conventional farming. Agriculture, Ecosystems and Environment, 118: 273-284.

[8] Tsvetkov, Y., Tsvetkov, I., N. Taneva and N. Kovachev, 2010.Possibilities for using of Kompovet B4 (waste product of BiovetPeshtera J.S.C.) for natural fertilizing of fructiferous hop variety Perla. Bulgarian Journal of Ecological Science "Ecology and Future", IX (3-4): 47-51.

[9] Babrikov, D., Todorov, H., L. Radulov and D. Braikov,
1989.Viticulture (in Bulgarian).Zemizdat (eds.), pp. 166178.

[10] Pimentel, D., Hepperly, P., Hanson, J., D. Douds and R. Seidel, 2005.Environmental, Energetic, and Economic Comparisons of Organic and Conventional Farming Systems.BioScience, 55 (7): 573- 582

[11] Lanini, W., G. McGourty, and L. Thrupp, 2011. Weed management for organic vineyards. In Organic Winegrowing Manual (G. McGourty (ed.), University of California, Agriculture and Natural Resources, Richmond, pp. 69-82.

[12] Karklelienè, R., Radzevičius, A., Dambrauskienè, E., Duchovskienè, L., Č. Bobinas and D. Kavaliauskaite, 2009. Reproduction features of organically grown edible carrot cultivars (DaucussativusRöhl.) in Lithuania. Agronomy Research, 7(I): 305- 310.

[13] Pinamonti, F. 1998. Compost mulch effects on soil fertility, nutritional status and performance of grapevine. Nutr.Cycl.Agroeco, 51: 239-248.

[14] Coventry, J.M., K.H. Fisher, and J.N. Strommer.2005. Reflective mulch to enhance berry quality on Ontario wine grapes.ActaHortic., 689: 95-101.

[15] Guerra, B. and K. Steenwerth, 2012.Influence of Floor Management Technique on Grapevine Growth, Disease Pressure, and Juice and Wine Composition: A Review. Am. J. Enol. Vitic., 63(2): 149-164.

[16] Tsvetkov, I. and Y. Tsvetkov, 2005.Bionematological effectiveness of Kompovet B 4 (waste product of Biovet JSC Pestera) on in vitro obtained vine crops. Biotechnology \& Biotechnology Equipment, 3(19): 74- 76.

[17] Tsvetkov, Y., N. Taneva and I. Tsvetkov, 2008.Possibility of using Kompovet B-4 for natural fertilization in fructi-ferous vineyards. Journal of Mountain Agriculture on the Balkans, 11(5): 920-929.

[18] Tsvetkov, Y., Tsvetkov, I., N. Taneva and N. Kovachev, 2010.Possibilities for using of Kompovet B4 (waste product of BiovetPeshtera JSC) for natural fertilizing of fructiferous hop variety Perla. Bulgarian Journal of Ecological Science "Ecology and Future", IX(3-4): 47-51.

[19] Villanueva- Rey, P., Vazquez- Rowe, I., M. Moreira and G. Feijoo, 2013.Comparative life cycle assessment in the wine sector: biodynamic vs. conventional viticulture activities in NW Spain. Journal of Cleaner Production, 1: 1-12.

[20] OIV, 2012. Report on World Vitiviniculture. International Organisation of Vine and Wine.Statistical. Available on line http://www.oiv.int/oiv/files/0\%20-\%20Actualites/EN/Report 